\title{
Percepções de estudantes dos anos iniciais do Ensino Fundamental sobre o Bioma Pampa
}

\section{PERCEPTIONS OF STUDENTS FROM THE EARLY YEARS OF FUNDAMENTAL EDUCATION ABOUT THE PAMPA BIOME}

\section{Luiza Frigo Pinto'; Bruna Ambros Baccin²; Luis Roberval Bortoluzzi Castro³; Edward Frederico Castro Pessano ${ }^{4}$}

1 Doutoranda, Universidade Federal do Pampa, Uruguaiana, Rio Grande do Sul, Brasil - luiza.frigo@yahoo.com.br,/ https://orcid.org/0000-0002-9476-5949

2 Doutoranda, Universidade Federal de Santa Maria, Santa Maria, Rio Grande do Sul, Brasil - brunabaccin@ hotmail.com,/ https://orcid.org/0000-0002-7017-9849

3 Doutorando, Universidade Federal do Pampa, Uruguaiana, Rio Grande do Sul, Brasil - lbortoluzzi@gmail.com,/ https://orcid.org/0000-0002-6272-5854

4 Doutor, Universidade Federal do Pampa, Uruguaiana, Rio Grande do Sul, Brasil - edwardpessano@unipampa.edu.br,/ https://orcid.org/0000-0002-6322-6416

Recebido em Dezembro/2018. Publicado em Abril/2020

Palavras-chave:

Anos iniciais 1.

Percepções 2.

Ecossistemas regionais 3. Bioma Pampa 4.

\section{Keywords:}

Early years 1 .

Perceptions 2. Regional ecosystems 3. Pampa biome 4 .
RESUMO: O ensino de Ciências nos anos iniciais deve oportunizar a criança explorar e aprender sobre o mundo natural e social no qual está inserida. Neste contexto, o estudo do bioma Pampa permite que os estudantes aprendam sobre as características existentes neste ecossistema, possibilitando a integração de conceitos científicos às questões do cotidiano, contribuindo no desenvolvimento de uma consciência crítica em relação aos problemas socioambientais. Neste sentido, este trabalho teve como objetivo investigar a percepção dos estudantes concluintes dos anos iniciais sobre o bioma Pampa, o qual foi desenvolvido em três escolas públicas dos municípios de Jaguari e Uruguaiana, com a participação de 84 estudantes. O estudo possui cunho qualitativo de caráter exploratório, onde para a coleta de dados, realizou-se a aplicação de questionários semiestruturados para a representação dissertativa, e de desenhos para a representação gráfica. Na interpretação dos dados utilizou-se a técnica de Análise de Conteúdo e nuvens de palavras. Os resultados permitem inferir, que os estudantes possuem percepções abrangentes e distorcidas sobre o ambiente natural, descrevendo o Pampa a partir de florestas, árvores, natureza, flores e rios. A antropização do ambiente natural foi observada através de elementos como o lixo, desmatamento, poluição e a urbanização. Apenas os desenhos de uma das escolas investigadas apresentaram elementos do Pampa, relacionados à cultura e da tradição gaúcha. Desse modo, entende-se a necessidade de que as crianças sejam sensibilizadas sobre a importância da preservação dos ecossistemas locais, através do empreendimento de ações e metodologias de ensino que possibilitem essa aprendizagem.

ABSTRACT: Science education in the early years should give children the opportunity to explore and learn about the natural and social world in which they are inserted. In this context, the study of the Pampa biome allows students to learn about the characteristics that exist in this ecosystem, enabling the integration of scientific concepts to everyday issues, contributing to the development of a critical awareness of socio-environmental problems. In this sense, this work aimed to investigate the perception of the concluding students of the initial years about the Pampa biome, which was developed in three public schools in the municipalities of Jaguari and Uruguaiana, with the participation of 84 students. The study has a qualitative nature 
of an exploratory nature, where for data collection, semi-structured questionnaires were applied for the essay representation, and drawings for the graphic representation. In the interpretation of the data it was used the technique of Content Analysis and word clouds. The results allow to infer, that the students have wide and distorted perceptions about the natural environment, describing the Pampa from forests, trees, nature, flowers and rivers. The anthropization of the natural environment was observed through elements such as garbage, deforestation, pollution and urbanization. Only the drawings of one of the investigated schools presented elements from Pampa, related to the culture and tradition of the state. In this way, it is understood the need for children to be sensitized about the importance of preserving local ecosystems, by undertaking actions and teaching methodologies that enable this learning.

\section{ENSINO, SAÚDE E AMBIENTE}

\section{PERCEPÇÕES DE ESTUDANTES DOS ANOS INICIAIS DO ENSINO FUNDAMENTAL SOBRE O BIOMA PAMPA}

\section{PERCEPTIONS OF STUDENTS FROM THE EARLY YEARS OF FUNDAMENTAL EDUCATION ABOUT THE PAMPA BIOME}

Palavras-chave:

Anos iniciais 1.

Percepções 2.

Ecossistemas regionais 3 . Bioma Pampa 4.

\section{Keywords:}

Early years 1 .

Perceptions 2. Regional ecosystems 3. Pampa biome 4.
RESUMO: O ensino de Ciências nos anos iniciais deve oportunizar a criança explorar e aprender sobre o mundo natural e social no qual está inserida. Neste contexto, o estudo do bioma Pampa permite que os estudantes aprendam sobre as características existentes neste ecossistema, possibilitando a integração de conceitos científicos às questões do cotidiano, contribuindo no desenvolvimento de uma consciência crítica em relação aos problemas socioambientais. Neste sentido, este trabalho teve como objetivo investigar a percepção dos estudantes concluintes dos anos iniciais sobre o bioma Pampa, o qual foi desenvolvido em três escolas públicas dos municípios de Jaguari e Uruguaiana, com a participação de 84 estudantes. O estudo possui cunho qualitativo de caráter exploratório, onde para a coleta de dados, realizou-se a aplicação de questionários semiestruturados para a representação dissertativa, e de desenhos para a representação gráfica. Na interpretação dos dados utilizou-se a técnica de Análise de Conteúdo e nuvens de palavras. Os resultados permitem inferir, que os estudantes possuem percepções abrangentes e distorcidas sobre o ambiente natural, descrevendo o Pampa a partir de florestas, árvores, natureza, flores e rios. A antropização do ambiente natural foi observada através de elementos como o lixo, desmatamento, poluição e a urbanização. Apenas os desenhos de uma das escolas investigadas apresentaram elementos do Pampa, relacionados à cultura e da tradição gaúcha. Desse modo, entende-se a necessidade de que as crianças sejam sensibilizadas sobre a importância da preservação dos ecossistemas locais, através do empreendimento de ações e metodologias de ensino que possibilitem essa aprendizagem.

ABSTRACT: Science education in the early years should give children the opportunity to explore and learn about the natural and social world in which they are inserted. In this context, the study of the Pampa biome allows students to learn about the characteristics that exist in this ecosystem, enabling the integration of scientific concepts to everyday issues, contributing to the development of a critical awareness of socio-environmental problems. In this sense, this work aimed to investigate the 
perception of the concluding students of the initial years about the Pampa biome, which was developed in three public schools in the municipalities of Jaguari and Uruguaiana, with the participation of 84 students. The study has a qualitative nature of an exploratory nature, where for data collection, semi-structured questionnaires were applied for the essay representation, and drawings for the graphic representation. In the interpretation of the data it was used the technique of Content Analysis and word clouds. The results allow to infer, that the students have wide and distorted perceptions about the natural environment, describing the Pampa from forests, trees, nature, flowers and rivers. The anthropization of the natural environment was observed through elements such as garbage, deforestation, pollution and urbanization. Only the drawings of one of the investigated schools presented elements from Pampa, related to the culture and tradition of the state. In this way, it is understood the need for children to be sensitized about the importance of preserving local ecosystems, by undertaking actions and teaching methodologies that enable this learning.

\section{INTRODUÇÃO}

O ensino de Ciências vem enfrentando inúmeras reformas educacionais, e na medida em que a Ciência e a Tecnologia foram sendo reconhecidas como primordiais para o desenvolvimento socioeconômico e cultural, o ensino das Ciências também foi crescendo de importância (KRASILCHIK, 2000). Nessa perspectiva, o ensino de Ciências, assume um papel muito importante na vida das pessoas, orientando-se para a promoção da cidadania, contribuindo com o desenvolvimento de sujeitos enquanto cidadãos, a fim de que possam realizar escolhas conscientes e intervir responsavelmente no meio em que vivem. (AULER, DELIZOICOV, 2001).

Nos espaços escolares do Brasil, ainda é possível constatar a ocorrência de um ensino de Ciências descontextualizado, onde os estudantes apenas memorizam o conteúdo sem relacionar com questões do cotidiano, ocasionado assim, a falta de estímulo e interesse nas aulas (UNESCO, 2005). Nesse sentido, o papel do professor deve favorecer a descoberta e a investigação científica, para que os estudantes possam redescobrir o já conhecido pela Ciência, e assim construir novos conceitos sobre os fenômenos naturais e as inter-relações entre o ser humano, o meio ambiente e as tecnologias (BRASIL, 1997; VIECHENESKI, LORENZETTI, CARLETTO, 2012).

A Base Nacional Comum Curricular - BNCC - (BRASIL, 2018) indica que o ensino das Ciências deve capacitar o estudante a compreender, interpretar o mundo, e transformá-lo com base nos aportes teóricos e processuais das Ciências. Por isso, a importância do letramento científico, desde as primeiras fases da educação, onde o ensino e a aprendizagem das Ciências possam ser compreendidos como um processo de enculturação científica (CARVALHO, 2009; SASSERON, 2015).

Desta forma, os conteúdos desenvolvidos dentro da sala de aula precisam ser além de relevantes e significativos, contextualizados, a fim de auxiliar nas questões socioambientais, culturais e científicas (PÉREZ, CARVALHO, 2012; PESSANO et al., 2013). Devido à 
necessidade de formar sujeitos atuantes em uma sociedade marcada pela presença da Ciência e Tecnologia, espera-se que o ensino de Ciências contribua desde os primeiros anos da escolarização, para que as crianças tenham compreensão do mundo e das transformações que nele ocorre, e assim saibam interpretar os conceitos científicos aprendidos (VIECHENESKI, CARLETTO, 2011).

Cabe destacar ainda, a importância de uma abordagem contextualizada no ensino de Ciências em uma perspectiva crítica, levando em consideração a problemática ambiental e as interações entre diferentes dimensões da Ciência. A Ciência-Tecnologia-Sociedade-Ambiente (CTSA) contribui para uma imagem mais completa e integrada da Ciência, e é considerada por alguns autores (GIL, VILCHES, 2004; FERNANDES, PIRES, DELGADO-IGLESIAS, 2018) como uma resposta à situação de emergência planetária, contribuindo para o desenvolvimento de uma consciência crítica, com vistas para um amanhã sustentável.

Nesta abordagem, o ensino de Ciências nas primeiras etapas da escolarização tornase fundamental na perspectiva de garantir que as crianças desde muito cedo desenvolvam competências e habilidades possibilitadas por essa inserção. De acordo com os autores Fracalanza, Amaral, Gouveia (1986):

\footnotetext{
“... o ensino de ciências no primeiro grau, entre outros aspectos, deve contribuir para o domínio das técnicas de leitura e escrita; permitir o aprendizado dos conceitos básicos das ciências naturais e da aplicação dos princípios aprendidos a situações práticas; possibilitar a compreensão das relações entre a ciência e a sociedade e dos mecanismos de produção e apropriação dos conhecimentos científicos e tecnológicos; garantir a transmissão e a sistematização dos saberes e da cultura regional e local" (FRACALANZA, AMARAL, GOUVEIA, 1986, p. 26-27).
}

Destaca-se que o envolvimento das crianças em situações investigativas como identificar e questionar sobre um problema, expor suas ideias, curiosidades e levantar hipóteses, é imprescindível para uma aprendizagem satisfatória, e por isso o ensino de Ciências deve estar presente desde a fase inicial, contribuindo para os processos formativos futuros.

De acordo com o Referencial Curricular Gaúcho (RCG) para o currículo na área de Ciências da Natureza, este apresenta uma proposta de concepção do conhecimento contextualizado na realidade local, social e individual do estudante (RIO GRANDE DO SUL, 2018, p. 49), e conforme este documento:

“[...] a ciência tem como objetivo que o estudante consiga compreender e interpretar o mundo, bem como transformá-lo, tendo consciência de suas ações e consequências, as quais podem interferir no ambiente em eu vive tornando a sociedade mais sustentável.” (RIO GRANDE DO SUL, 2018, p. 49).

Assim, a distância dos conteúdos ensinados para a realidade dos estudantes, faz com que eles tenham dificuldades em aprender, impossibilitando a visualização dos problemas 
reais, pois não conseguem estabelecer uma relação entre os conteúdos com o ambiente natural a sua volta, tampouco possibilita o desenvolvimento de atitudes críticas.

A partir de tais apontamentos, a presente pesquisa buscou investigar a percepção dos estudantes de escolas estaduais do $5^{\mathrm{a}}$ ano do Ensino Fundamental sobre o bioma Pampa. Uma vez que, a investigação da percepção ambiental possibilita compreender as diferentes percepções dos estudantes sobre o ambiente. A percepção ambiental é utilizada para identificar pontos positivos e negativos na relação entre ser humano e meio ambiente. Em um sentido fenomenológico a percepção ambiental é conceituada como uma tomada de consciência do ser humano sobre o meio ambiente, e a forma como eles se relacionam (SANTOS, SARTORELLO, 2019).

\section{O BIOMA PAMPA COMO TEMA DE INVESTIGAÇÃO}

O bioma Pampa ocupa uma extensa região natural com mais de 750 mil $\mathrm{Km}^{2}$, que abrange todo o Uruguai, centro-leste da Argentina, no Brasil está restrito apenas a um Estado, o Rio Grande do Sul (RS) (BOLDRINI et al., 2010; BENCKE, CHOMENKO, SANTANA, 2016). Reconhecido oficialmente a partir de 2004, ocupa uma área aproximadamente de $177.767 \mathrm{~km}^{2}$, que corresponde a 2,07\% do território nacional e $63 \%$ do território RioGrandense (BRASIL, 2011).

A história do Pampa no convívio com a cultura humana, segundo Suertegaray e Silva (2009), era de servir como um grande cocho no decorrer de 300 anos para a produção pecuária. Termo de origem quíchua (ou quechua), Pampa, na língua aborígene da América do Sul, também falada no império Inca, significa "região plana", associado às paisagens com extensas planícies cobertas de vegetação rasteira, caracterizando o extremo Sul do Brasil, compartilhando esta vegetação campestre com os países das Repúblicas Platinas (SUERTEGARAY, SILVA, 2009; BENCKE, CHOMENKO, SANT’ANNA, 2016).

Os campos nativos constituem o tipo de vegetação natural na paisagem, constituindo a maior extensão de ecossistemas campestres de clima temperado do continente SulAmericano (BENCKE, CHOMENKO, SANT'ANNA, 2016). Apresenta grande biodiversidade de espécies e de ecossistemas adaptadas ao seu habitat e raramente encontrada em outros biomas, deixando o Pampa entre os que apresentam umas das maiores diversidades de fauna e flora do mundo (BENCKE, CHOMENKO, SANT'ANNA, 2016). Os autores Boldrini et al. (2010) definem a estrutura vegetacional existente no bioma Pampa como:

Embora aos olhos do leigo possa parecer simples e uniforme, trata-se de um bioma complexo, composto por várias formações vegetacionais dentre as quais o campo dominado por gramíneas é o mais representativo. A matriz geral é formada por áreas extensas de campos, com inclusões de florestas pelas margens de rios. (BOLDRINI et al., 2010, p. 10). 
A devastação dos campos do bioma Pampa, segundo Castro (2018, p. 75) está relacionada "a intervenção humana descontrolada está diretamente associada à degradação ambiental, pois modificam os ecossistemas, afetam a biodiversidade e está relacionada à perda da qualidade de vida das populações", e na degradação ambiental temos a conversão do campo nativo para as monoculturas (soja, arroz, milho), silviculturas (eucaliptos e pinus) e pecuária. A descaracterização das vegetações existentes e a perda dos habitats endêmicos resultam na eliminação de muitas espécies da flora e fauna, e do campo nativo presente no RS (OVERBECK et al., 2009; VERRASTRO, BORGES-MARTINS, 2015).

Acredita-se que na medida em que os estudantes reconhecem os ecossistemas da sua região, mais fácil será sua compreensão do meio em que vive, pois, normalmente, não percebem o ambiente natural na sua totalidade, desconhecendo os organismos que ali vivem e sua importância, gerando um sentimento de rejeição pela paisagem do ambiente habitado (TUAN, 1983; RODRIGUES, FARRAPEIRA, 2008).

Neste sentido, entende-se ser fundamental o conhecimento dos ecossistemas locais, pois estão diretamente relacionados à cultura de determinadas regiões, e nesse sentido os autores Cruz e Guadagnin (2010, p. 166) explicam que o “[...] Pampa que existe hoje, e que deve ser preservado, gerou e foi gerado pelo gaúcho. Pode-se afirmar que houve uma coevolução entre a cultura do gaúcho e o sistema de campos atual do bioma Pampa.”, por isso, é necessário que aconteça a sensibilização dos estudantes sobre os temas ambientais relacionados ao Pampa.

Para tanto, é necessário o levantamento das percepções prévias dos estudantes para assim, direcionar a ação educativa, corrigindo percepções negativas da paisagem e ressaltar a importância do ambiente despercebido, associando atitudes e valores à preservação dos ambientes relacionados ao contexto dos estudantes (PESSANO et al., 2013).

\section{A IMPORTÂNCIA DO CONHECIMENTO DOS ECOSSISTEMAS REGIONAIS}

Conforme Bizzo (2009, p.16) “[...] ensinar ciências no mundo atual deve constituir uma das prioridades para todas as escolas, que devem investir na edificação de uma população consciente e crítica diante das escolhas e decisões a serem tomadas.", possibilitando a integração entre os conceitos científicos às questões do cotidiano, principalmente na conscientização dos problemas socioambientais onde o estudante mora.

Conforme a BNCC, nos anos inicias do Ensino Fundamental é necessário que aconteça a valorização dos ambientes que cercam os estudantes, oportunizando a interação, a compreensão e ações no seu entorno, reconhecendo a importância da preservação da 
biodiversidade, e, como ela se distribui nos principais ecossistemas brasileiros (BRASIL, 2018). Ainda segundo a BNCC:

Nos anos iniciais, as características dos seres vivos são trabalhadas a partir das
ideias, representações, disposições emocionais e afetivas que os alunos trazem para
a escola. Esses saberes dos alunos vão sendo organizados a partir de observações
orientadas, com ênfase na compreensão dos seres vivos do entorno, como também
dos elos nutricionais que se estabelecem entre eles no ambiente natural. (BRASIL,
2018, p. 324)

Em contribuição, o Referencial Curricular Gaúcho "propõe o estudo de questões relacionadas aos seres vivos, suas características e a vida como fenômeno natural e social [...] e também as características dos ecossistemas, destacando-se as interações entre os dos seres vivos e os fatores não vivos do ambiente.” (RIO GRANDE DO SUL, 2018, p.49).

O processo de degradação ambiental está acelerado em todo planeta (WAGLER, WAGLER, 2011), sendo difícil a previsão de resultados positivos (ROCKSTRÖM et al., 2009). Diante deste cenário, muitos autores defendem veementemente a conscientização de jovens desde a infância (KELLERT, 1993; SNADDON, TURNER, 2007; SNADDON et al., 2008). Pois, se as crianças não tiverem a possibilidade de se familiarizar com seu próprio ambiente natural, terão consideráveis problemas em abordar questões relacionais à biodiversidade assim como os problemas ecológicos (WEILBACHER,1993; HEYWOOD, 1995).

A percepção dos ecossistemas regionais é fundamental para a promoção da consciência ambiental, e neste sentido, é preciso promover formações atualizadas sobre o ensino de Ciências para os professores. Os autores Soares, Mauer, Kortmann (2013) mencionam que os professores polivalentes dos anos iniciais têm poucas oportunidades de conhecer o ensino de Ciências e suas metodologias. A ausência de aporte dos conhecimentos estruturados em Ciências e das demais disciplinas torna o ato de ensinar um desafio para esses educadores (BATISTA, FUSINATO, RAMOS, 2017).

A Educação Ambiental, como ferramenta interdisciplinar, surgiu para suprir às necessidades da educação formal sobre as questões ambientais, e também para proporcionar uma nova visão sobre o meio ambiente (SOUSA et al., 2011), principalmente dos ecossistemas regionais, e assim, compreendam a importância da preservação ambiental.

As questões ambientais abordadas no ensino de Ciências contribuem no desenvolvimento de ações conscientes para a preservação da biodiversidade local, assim surge a necessidade de trabalhar temáticas ambientais de forma contextualizadas, pois são ferramentas essenciais no desenvolvimento educacional dos conteúdos presentes no cotidiano dos estudantes (PESSANO et al., 2013). 
Assim sendo, a abordagem da Educação Ambiental torna-se essencial, em todos os níveis de ensino, mas principalmente nos anos iniciais, pois é mais fácil conscientizar as crianças da importância do ambiente natural, do que reeducar os adultos (BRONDANI, HENZEL, 2010).

\section{PERCURSO METODOLÓGICO}

A presente pesquisa faz parte de um projeto maior, tratando-se de um recorte de uma dissertação de mestrado, a qual foi aprovada pelo Comitê de Ética em Pesquisa da Universidade CAAE: 60374216.3.0000.5323, parecer de aprovação do projeto $\mathrm{n}^{\circ}: 1.840 .202 \mathrm{e}$ parecer de aprovação da coleta de dados $n^{\circ}: 2.063 .911$ atendendo aos termos da Resolução 466/12.

Inicialmente realizou-se uma breve pesquisa bibliográfica sobre outras pesquisas relacionadas ao bioma Pampa e ao ensino de ciências, onde foi efetuada uma busca nos principais repositórios de pesquisas científicas - Scielo, Biblioteca Digital Brasileira de Teses e Dissertações (BDTD) e nos Encontro Nacional de Pesquisas em Educação em Ciências (ENPECs) no período de 2010 - 2018.

A coleta dos dados aconteceu em dois munícipios do RS, Jaguari e Uruguaiana, no segundo semestre de 2017. O motivo para a escolha destes municípios deu-se por motivos diferentes, no caso de Uruguaiana se deve ao fato de estar situada exclusivamente no bioma Pampa, localizado no extremo oeste do Estado do RS. Ocupando a $4^{\mathrm{a}}$ posição entre as cidades com maior índice de antropização do pampa gaúcho, mas apresenta uma grande importância biológica (CASTRO, 2018). O município de Jaguari localiza-se no Centro-Oeste do Estado do RS, e situa-se em área limítrofe, com influência do bioma Mata Atlântica e bioma Pampa, é uma região classificada de extrema importância biológica, mas não contém nenhuma Unidade de Conservação, e ainda, é pouco estudada (PAZ, ROMANOWSKI, MORAIS, 2014).

A partir da autorização das escolas e o recolhimento do termo de consentimento livre e esclarecido dos estudantes, deu-se início a pesquisa. Para apresentar os resultados da pesquisa neste trabalho, as escolas participantes foram identificadas por letras, em Jaguari foram duas escolas, uma situada na área urbana (A), e outra situada na área rural (B). Já em Uruguaiana foi realizada na escola situada na área urbana (C), sendo a escola piloto da pesquisa.

O tamanho amostral foi definido com base nos estudantes que manifestaram interesse e que obtiveram autorização dos responsáveis para participar da pesquisa, totalizando uma amostra de oitenta e quatro $(n=84)$ estudantes investigados. Frente a isso, as escolas nesta pesquisa são identificadas neste estudo como A, B, C como mencionado anteriormente, já os 
estudantes pesquisados, foram identificados por letras, sendo do E1 ao E25 representam escola A, do E26 ao E 41 da escola B, e por fim, do E42 a E84 a escola C.

Os dados foram coletados através de questionários semiestruturados, constituído por duas seções, a primeira referente ao perfil dos estudantes (idade e gênero) e a segunda dividida em três blocos (QUADRO 1) com oito questões.

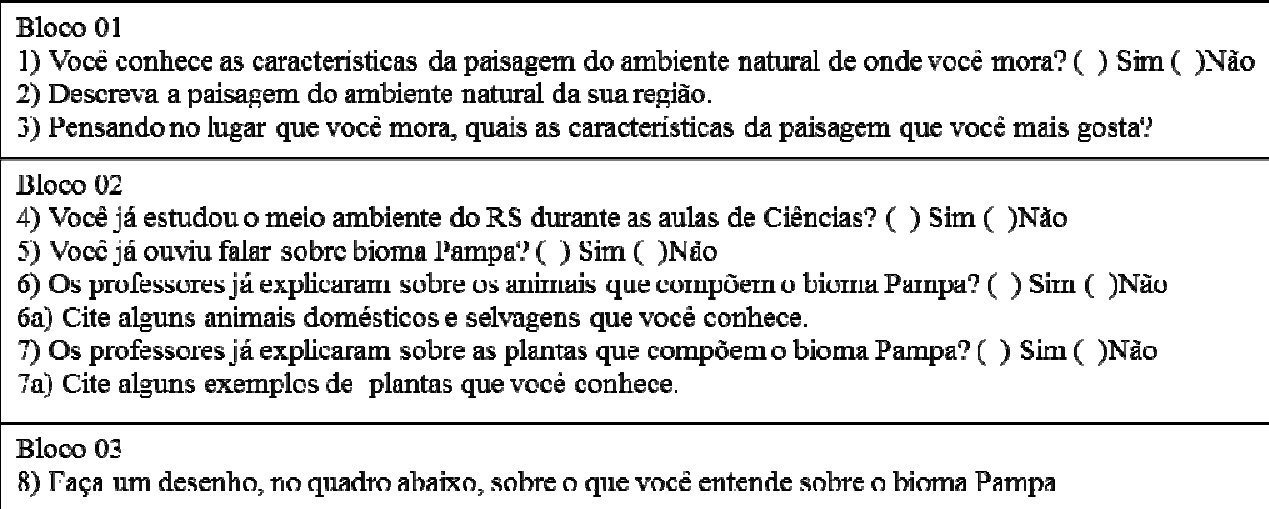

Quadro 01: Questionário aplicado aos estudantes Fonte: Dados da pesquisa

O quadro 01 apresenta as questões aplicadas aos estudantes através do questionário, no bloco 01 verificou-se a percepção dos estudantes do lugar onde moravam, a descrição do ambiente natural, e quais paisagens gostavam. Já através das questões do bloco 2 verificou-se as percepções sobre os temas meio ambiente, bioma Pampa, animais e plantas da região. $\mathrm{Na}$ questão do bloco 3 solicitou-se à elaboração de uma representação gráfica (desenho) livre sobre o bioma Pampa, onde buscou-se fazer uma associação com as questões descritivas, a fim de analisar se os estudantes percebem o ambiente natural como o bioma Pampa.

A pesquisa tem caráter qualitativo, sendo uma investigação científica exploratória e busca informações sobre as características e/ou opiniões de determinado grupo de indivíduos representantes de uma população-alvo (CASTRO, 2018).

Para a análise qualitativa dos dados foi utilizada a metodologia de Análise de Conteúdo (BARDIN, 2011), onde tal metodologia foi escolhida de acordo com Minayo (2001, p. 74) o qual enfatiza que a análise de conteúdo visa verificar hipóteses e ou descobrir o que está por trás de cada conteúdo manifesto, o que está escrito, falado, mapeado, figurativamente desenhado e/ou simbolicamente explicitado, e sempre será o ponto de partida para a identificação do conteúdo manifesto (seja ele explícito e/ou latente), onde cada resposta é tratada com profundidade.

Para a análise das questões 6a e 7a do bloco 02 (Quadro 01), utilizou-se a técnica Nuvens de Palavras que se configura como outra possibilidade de análise qualitativa através 
Ensino, Saúde e Ambiente - V13 (1), pp. 31-56, Abr. 2020

de nuvens de palavras ${ }^{1}$ (Word Art). A técnica de construção destas nuvens consiste em usar tamanhos e fontes de letras diferentes de acordo com a frequência das ocorrências das palavras no texto analisado (PRAIS, ROSA, 2017). Esta forma mais visual pode contribuir para a compreensão e tem a facilidade de ser executada rapidamente, através de sítios da internet.

Para a interpretação das representações artísticas (desenhos) de acordo com a Análise de Conteúdo, inicialmente realizou-se uma pré-analise, exploração dos materiais, e por fim a interpretação, onde a partir dessa análise, observando critérios como a presença de elementos que representassem a urbanização do ambiente, seus problemas ambientais, elementos do campo e rurais, foram criadas duas categorias, conforme segue:

- Paisagem Urbanizada: Nesta categoria foram agrupados os desenhos que apresentavam em sua estrutura elementos prediais, vias urbanas, poluição e da influência humana na transformação da paisagem.

- Paisagem Rural: Nesta categoria foram agrupados os desenhos que apresentavam em sua estrutura elementos voltados ao campo, onde o destaque é o relevo, a vegetação e os animais, sem construções prediais aglomeradas.

\section{RESULTADOS E DISCUSSÃO}

Partindo do objetivo proposto neste trabalho de investigar a percepção dos estudantes de três escolas públicas do $5^{\circ}$ ano do ensino fundamental sobre o bioma Pampa, obteve-se a participação de 84 estudantes concluintes dos anos iniciais.

Em relação à pesquisa bibliográfica realizada nos principais repositórios de pesquisas científicas - Scielo, Biblioteca Digital Brasileira de Teses e Dissertações (BDTD) e nos Encontro Nacional de Pesquisas em Educação em Ciências (ENPECs) no período de 2010 2018, sobre pesquisas relacionadas ao bioma Pampa no ensino de Ciências dos anos iniciais, verificou-se a inexistência de trabalhos publicados nas bases de dados avaliadas. Tal dado demonstra a importância e a possível contribuição que o presente trabalho poderá efetuar para futuras ações dentro dos espaços escolares, com vistas a melhorias nos processos de ensino e o conhecimento deste importante ecossistema.

O grupo mais representativo, entre os entrevistados foi da escola $\mathrm{C}$, com a participação de 43 estudantes, seguido da escola A com 25 estudantes e a escola B com 16 estudantes. Cabe salientar, que esta pesquisa não se ocupou em investigar o perfil socioeconômico dos investigados, por entender que esse dado não interfere nos resultados da pesquisa.

\footnotetext{
${ }^{1}$ Home Page utilizada na elaboração das nuvens de palavras do estudo: https://wordart.com
} 
A idade dos pesquisados variou de 10 a 14 anos, sendo que a idade de 10 anos representou 47\% seguida das idades de, 11 anos 42\%, 12 anos 8\%, 13 anos 2\% e 14 anos 1\% dos pesquisados e quanto as escolas a unidade A representou $30 \%$, a B $19 \%$ e a C $51 \%$ da amostra (Tabela 01). Com base nos documentos oficinais a faixa etária para o $5^{\circ}$ ano do ensino fundamental corresponde dos 10 aos 11 anos de idade (BRASIL, 2009).

Tabela 01 - Idades dos estudantes por escola

\begin{tabular}{|c|c|c|c|c|c|c|c|c|}
\hline \multirow{2}{*}{\multicolumn{2}{|c|}{ Escolas }} & \multicolumn{5}{|c|}{ IDADES DOS PESQUISADOS } & \multirow{2}{*}{$\begin{array}{l}\text { Total por } \\
\text { Escola } n\end{array}$} & \multirow{2}{*}{$\begin{array}{l}\text { Total por } \\
\text { Escola \% }\end{array}$} \\
\hline & & 10 & 11 & 12 & 13 & 14 & & \\
\hline \multirow{2}{*}{ A } & $\%$ & $40 \%$ & $40 \%$ & $16 \%$ & $4 \%$ & $0 \%$ & \multirow{2}{*}{25} & \multirow{2}{*}{$30 \%$} \\
\hline & $N$ & 10 & 10 & 4 & 1 & 0 & & \\
\hline \multirow{2}{*}{ B } & $\%$ & $38 \%$ & $62 \%$ & 0 & 0 & 0 & \multirow{2}{*}{16} & \multirow{2}{*}{$19 \%$} \\
\hline & $N$ & 6 & 10 & 0 & 0 & 0 & & \\
\hline \multirow{2}{*}{$\mathbf{C}$} & $\%$ & $53 \%$ & $35 \%$ & $7 \%$ & $2 \%$ & $2 \%$ & \multirow{2}{*}{43} & \multirow{2}{*}{$51 \%$} \\
\hline & $N$ & 23 & 15 & 3 & 1 & 1 & & \\
\hline \multirow[t]{2}{*}{ TOTAL } & $\%$ & $47 \%$ & $42 \%$ & $8 \%$ & $2 \%$ & $1 \%$ & & \multirow[t]{2}{*}{$100 \%$} \\
\hline & $\mathrm{N}$ & 39 & 35 & 7 & 2 & 1 & 84 & \\
\hline
\end{tabular}

Fonte: Dados da pesquisa

Quanto ao questionário aplicado, a primeira pergunta foi sobre o conhecimento da paisagem do ambiente natural de onde os estudantes residem. As respostas indicaram que a maioria dos estudantes conhecem as características da paisagem (Tabela 02).

Tabela 02 - Respostas sobre as características da paisagem

\begin{tabular}{cc|c|c|c|c|c}
\hline Você conhece as & \multicolumn{2}{|c|}{ Escola A } & \multicolumn{2}{c|}{ Escola B } & \multicolumn{2}{c}{ Escola C } \\
características da & Sim & Não & Sim & Não & Sim & Não \\
paisagem do & $92 \%$ & $8 \%$ & $100 \%$ & & $70 \%$ & $30 \%$ \\
$\begin{array}{c}\text { ambiente natural de } \\
\text { onde você mora? }\end{array}$ & $\mathrm{n}=23$ & $\mathrm{n}=2$ & $\mathrm{n}=16$ & & $\mathrm{n}=30$ & $\mathrm{n}=13$ \\
\hline
\end{tabular}

Fonte: Dados da pesquisa

Destaca-se, que os estudantes da escola B, responderam afirmativamente a esta pergunta, o que permite inferir que o cotidiano dos estudantes pode ter influenciado consideravelmente, uma vez que, a escola localiza-se na área rural.

$\mathrm{Na}$ análise das respostas da questão 02 , onde foi solicitado aos estudantes a descrição de como era a paisagem natural da sua região, as respostas variaram entre as palavras como o "lixo", as "árvores", as "plantas" e as "flores", entre outras. A partir das respostas obtidas, foram construídas nuvens de palavras de acordo com cada escola investigada (Figura 01). 


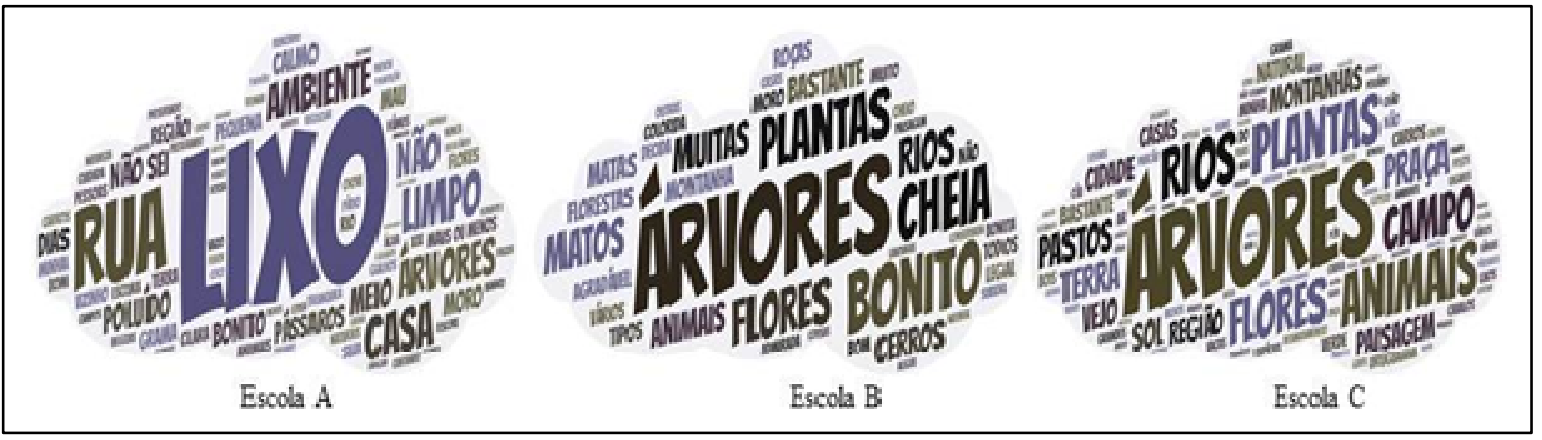

Figura 01- Descreva a paisagem do ambiente natural da sua região.

Fonte: Dados da pesquisa

Pode-se analisar que na escola $\mathrm{A}$ as respostas evidenciaram as questões ambientais presentes no cotidiano, E14: "Muito lixo nas minhas ruas as pessoas largam os lixos pensando que a rua é uma lixeira muito grande"; E21: "Ele tem alguns lixos mas ele até que ele é cuidado".

$\mathrm{Na}$ escola $\mathrm{B}$, as palavras remetem ao ambiente mais natural, sem elementos de poluição, onde responderam E28: "Ela é cheia de seros, matos, arvores, rios, plantas, flores, roças, etc."; E40: "La tem muitas arvores, matos, plantas, lavouras, casas e outras coisas.".

$\mathrm{Na}$ escola $\mathrm{C}$, as palavras em destaque evidenciam um ambiente natural, mas com alguns elementos relativos a degradação do ambiental, E47: “Campos verdes com varias especies de animais bois, vacas, cavalos, cabra e grandes estabulos e poços"; E55: "eu sempre vejo nas ruas que jogam lixos no guão e não jugão na ligeira”.

Seguindo com a análise das respostas do bloco 01, onde os estudantes foram questionados sobre as características do ambiente natural que mais gostavam, e as respostas também foram organizadas em nuvens de palavras (Figura 02).

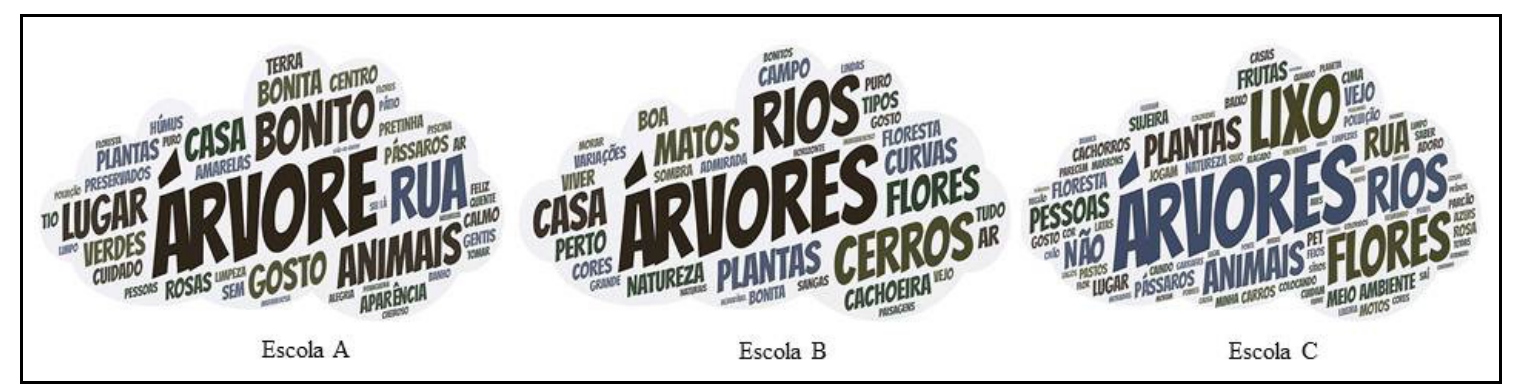

Figura 02 - Pensando no lugar onde você mora, quais características da paisagem que você mais gosta Fonte: Dados da pesquisa

Observa-se que na escola A, os elementos da paisagem que mais apareceram foram, "árvore", "rua", "animais", "bonita”, “casa”, com as seguintes respostas E10: "Da limpeza e sem poluencia e muita alegria"; E8: "Eu gosto que este lugar é calmo, bem bonito, as pessoas são gentis, tem muitos animais.".

$\mathrm{Na}$ escola $\mathrm{B}$, através da análise das respostas, pode-se inferir que os estudantes possuem a preferência pelas "árvores"; "rios", "cerros", "flores”, "casa", "matos", o que pode ser observado nas seguintes respostas: E28: "Ela é cheia de seros, matos, arvores, rios, plantas, 
flores, roças, etc.”; E39: “La tem muitas arvores, matos, plantas, lavouras, casas e outras coisas.”. Dentre as paisagens preferidas apareceu o "campo", como na resposta do estudante E31: "Campo", sendo que para esta pergunta somente nesta escola obteve-se essa resposta.

$\mathrm{Na}$ nuvem de palavras da escola $\mathrm{C}$, as palavras em destaque, ou seja, as que mais apareceram nas respostas foram "árvores", "rios", "animais", "lixo", "plantas", "ruas", como pode ser observado nas seguintes respostas: E57: "bom, eu adoro as árvores e eu adoro ainda mais é quando elas ficam flores e os passaros coloridos."; E73: "Transitos de carros e motos"; E84: "Os lixos reciclavéis e as árvores".

Os elementos mais citados pelos estudantes, como árvores, pássaros, rios, animais, flores e natureza, também foram encontrados em outras pesquisas com crianças sobre as percepções ambientais (PROFICE et al., 2013; SCHWARZ et al., 2016).

Entretanto, a palavra "árvores" teve maior destaque nas imagens, seguindo das palavras "lixo", "plantas", "flores", entre outras. E de acordo com os autores Aires e Basto (2011, p. 359) "“...] a referência repetitiva destes elementos constitui um forte indicador da ligação afetiva dos estudantes com o ambiente, e revela, também, o modo de perceber esse lugar $[\ldots]$ ". , pois alguns elementos foram citados em todas as nuvens de palavras analisadas.

Ao analisarmos as nuvens de palavras geradas em ambas as questões, pode-se observar que alguns problemas ambientais foram citados, e conforme Martinho e Talamoni $(2007$, p.2)

Torna-se urgente e necessária, portanto, a discussão dessas questões na escola, desde a mais tenra idade. Porém, não numa perspectiva mistificadora, ou como modismo, mas possibilitando ao aluno uma reavaliação crítica perante os problemas ambientais. (MARTINHO, TALAMONI, 2007, p.2)

Nesse sentido, é necessário que as crianças aprendam sobre a importância da preservação e conservação do meio ambiente, desde o início da escolarização, para desenvolverem uma consciência sobre a urbanização do ambiente natural. E assim, possam se posicionar de forma crítica e também preventiva com relação aos problemas decorrentes disso, para o meio ambiente.

Ainda, analisando as nuvens de palavras acima, verifica-se que os estudantes apresentam percepções abrangentes sobre o bioma Pampa como ambiente natural. Como pode ser analisado através das respostas obtidas. $\mathrm{Na}$ escola $\mathrm{C}$ os estudantes apresentaram descrições como: E46: "Cavalos, campos, lavouras, piquetes, árvores, plantas"; E47: "Campos verdes com varias especies de animais bois, vacas, cavalos, cabra e grandes estabulos e poços"; E59: “Campos - arvores - plantas - bichos - flores - terra."; E70: “Coxilhas”; E71: “tem muitos campos e árvores e muitos lugares bem cuidados pelos homens". 
Na escola A, obteve-se apenas uma resposta que remete ao tema pesquisado, exibindo uma visão imaginativa sobre o ambiente, como pode ser observado E12: "Bom, tem campos floridos, chove e as vezes tem trovões, sei que nunca nevou, mas teve dias gelados, e dias quentes para ir ao rio tomar banho.". A escola B apresentou uma característica do bioma Pampa, E31: "Campo".

Nas escolas A e B, localizadas em áreas limítrofes entre Mata Atlântica e bioma Pampa, foram citadas poucas características do bioma investigado, a maioria dos elementos remete a árvores, florestas, matas, rios, flores, natureza, que também foram citados pela escola C. A partir disso, infere-se que essas respostas estejam relacionadas ao contexto em que estas crianças vivem, ou com os conhecimentos escolares descontextualizados, e até mesmo sofrendo influência da mídia, através dos desenhos infantis ou programas assistidos (WORTMANN, RIPOLL, POSSAMAI, 2012).

Nas questões do Bloco 02, foram investigadas as percepções dos estudantes sobre os assuntos ambientais do RS, o conhecimento do Pampa, os animais e plantas que compõem o bioma, assim foram obtidos os seguintes resultados, conforme mostra tabela (Tabela 03).

Tabela 03 - Resultados das questões sobre as características do RS

\begin{tabular}{|c|c|c|c|c|c|c|}
\hline & \multicolumn{2}{|c|}{ Escola A } & \multicolumn{2}{|c|}{ Escola B } & \multicolumn{2}{|c|}{ Escola C } \\
\hline & Sim & Não & Sim & Não & Sim & Não \\
\hline $\begin{array}{l}\text { 4) Você já estudou sobre o } \\
\text { meio ambiente do RS durante } \\
\text { as aulas de Ciências? }\end{array}$ & $\begin{array}{l}80 \% \\
\mathrm{n}=20\end{array}$ & $\begin{array}{l}20 \% \\
\mathrm{n}=5\end{array}$ & $\begin{array}{l}87 \% \\
\mathrm{n}=14\end{array}$ & $\begin{array}{l}13 \% \\
\mathrm{n}=2\end{array}$ & $\begin{array}{l}65 \% \\
\mathrm{n}=28\end{array}$ & $\begin{array}{l}35 \% \\
\mathrm{n}=15\end{array}$ \\
\hline $\begin{array}{l}\text { 5) Você já ouviu falar sobre } \\
\text { bioma Pampa? }\end{array}$ & $\begin{array}{l}32 \% \\
\mathrm{n}=8\end{array}$ & $\begin{array}{l}68 \% \\
n=17\end{array}$ & $\begin{array}{c}25 \% \\
\mathrm{n}=4\end{array}$ & $\begin{array}{l}75 \% \\
\mathrm{n}=12\end{array}$ & $\begin{array}{l}35 \% \\
\mathrm{n}=15\end{array}$ & $\begin{array}{l}65 \% \\
\mathrm{n}=28\end{array}$ \\
\hline $\begin{array}{c}\text { 6) Os professores já } \\
\text { explicaram sobre os animais } \\
\text { que compõem o bioma } \\
\text { Pampa? }\end{array}$ & $\begin{array}{l}12 \% \\
n=3\end{array}$ & $\begin{array}{l}88 \% \\
n=22\end{array}$ & $\begin{array}{l}19 \% \\
\mathrm{n}=3\end{array}$ & $\begin{array}{l}81 \% \\
\mathrm{n}=13\end{array}$ & $\begin{array}{l}79 \% \\
\mathrm{n}=34\end{array}$ & $\begin{array}{l}21 \% \\
\mathrm{n}=9\end{array}$ \\
\hline $\begin{array}{l}\text { 7) Os professores já } \\
\text { explicaram sobre as plantas } \\
\text { que compõem o bioma } \\
\text { Pampa? }\end{array}$ & $\begin{array}{l}24 \% \\
\mathrm{n}=6\end{array}$ & $\begin{array}{l}76 \% \\
\mathrm{n}=19\end{array}$ & $\begin{array}{l}19 \% \\
\mathrm{n}=3\end{array}$ & $\begin{array}{l}81 \% \\
\mathrm{n}=13\end{array}$ & $\begin{array}{l}63 \% \\
n=27\end{array}$ & $\begin{array}{l}37 \% \\
\mathrm{n}=16\end{array}$ \\
\hline
\end{tabular}

Fonte: Dados da pesquisa

A análise das respostas demonstrou que embora se trabalhe com as características ambientais do RS, os estudantes não conseguem estabelecer relações com o bioma Pampa, não reconhecendo o ambiente que vivem. Por outro lado, pode-se inferir que talvez este tema possa não ter sido desenvolvido pelos professores ou até mesmo, tenham utilizado outro termo para sua definição. 
E de acordo com Paris et al. (2016) e Castro (2018), a conservação do Pampa é uma necessidade e o conhecimento por parte dos estudantes é uma condição essencial para a valorização, manutenção de sua biodiversidade e para o funcionamento dos processos ecossistêmicos. Em pesquisa de Profice et al. (2013) na grande maioria dos casos investigados, não há o reconhecimento da importância da vegetação nativa para a manutenção da biodiversidade no lugar onde vivem.

Em seguida, considerando a necessidade de trabalhar com temas relacionados a biodiversidade nativa, os estudantes foram questionados se os professores explicaram sobre os animais do bioma Pampa. Logo, de todos os estudantes investigados, apenas na escola C obtivemos respostas significativas, onde a maioria respondeu afirmativamente a pergunta, conforme expresso na questão 06 da tabela 03.

Conforme a questão 06a, a qual solicitava que o estudante citasse os animais domésticos e selvagens conhecidos, obteve-se diferentes respostas, que deram origem a diferentes nuvens de palavras, as quais foram dividas em animais domésticos e animais selvagens. Os animais domésticos citados podem ser observados na Figura (03) abaixo.

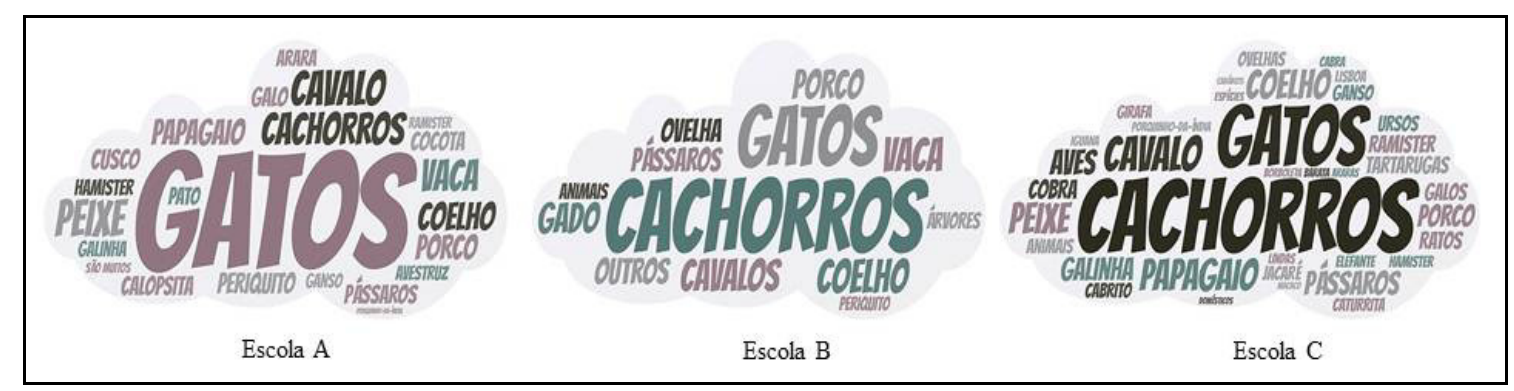

Figura 03 - Animais domésticos citados

Fonte: Dados da pesquisa

Como pode ser analisado nas nuvens de palavras, os animais domésticos mais citados nas respostas foram, cachorros, gatos, coelhos, galinhas, cavalos, entre outros, os quais de acordo com a portaria do Instituto Brasileiro do Meio Ambiente e dos Recursos Naturais Renováveis (IBAMA 093/98) são animais que através de processos tradicionais e sistematizados tornaram-se domésticos. Dados semelhantes a estes foram encontrados em pesquisa realizada por Almeida, Vasconcelos, Torres (2013).

Os animais selvagens citados pelos estudantes investigados podem ser observados na Figura (04) a seguir. 


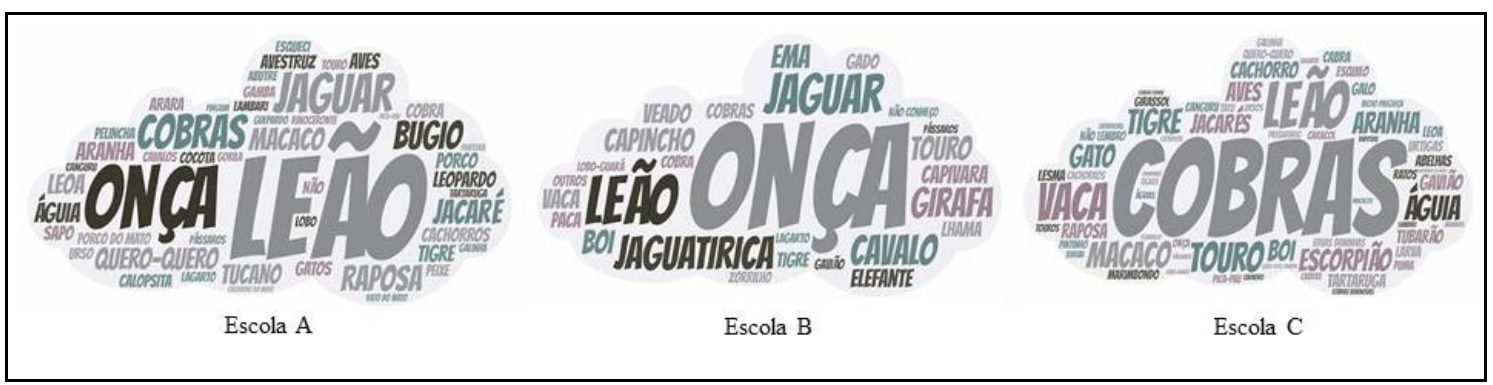

Figura 04 - Animais selvagens citados

Fonte: Dados da pesquisa

Entre os animais selvagens citados temos o "Bugio", "Quero-quero", "Capivara", "Ema", entre outros, destaca-se novamente a possível influência dos conhecimentos escolares, da mídia, notícias e dos desenhos infantis, pois alguns animais que não estão presentes no cotidiano foram citados, como "a Águia”, “o Leão”, “o Elefante” e "a Girafa”.

Observa-se que os estudantes citaram alguns animais domésticos, indicando uma confusão entre os conceitos de animais selvagens e domésticos, provavelmente, devido ao fato de não compreenderem totalmente esses conceitos, ou até mesmo, porque os animais domésticos são mais frequentes no cotidiano das famílias.

$\mathrm{Na}$ última questão proposta, os estudantes foram questionados se os professores já explicaram sobre as plantas que compõem o bioma Pampa. Apenas os estudantes da escola $\mathrm{C}$ responderam afirmativamente, enquanto que nas escolas A e B eles responderam apenas que não tinham estudado sobre esse assunto.

As plantas mais citadas pelos estudantes podem ser analisadas na figura abaixo (Figura 05).

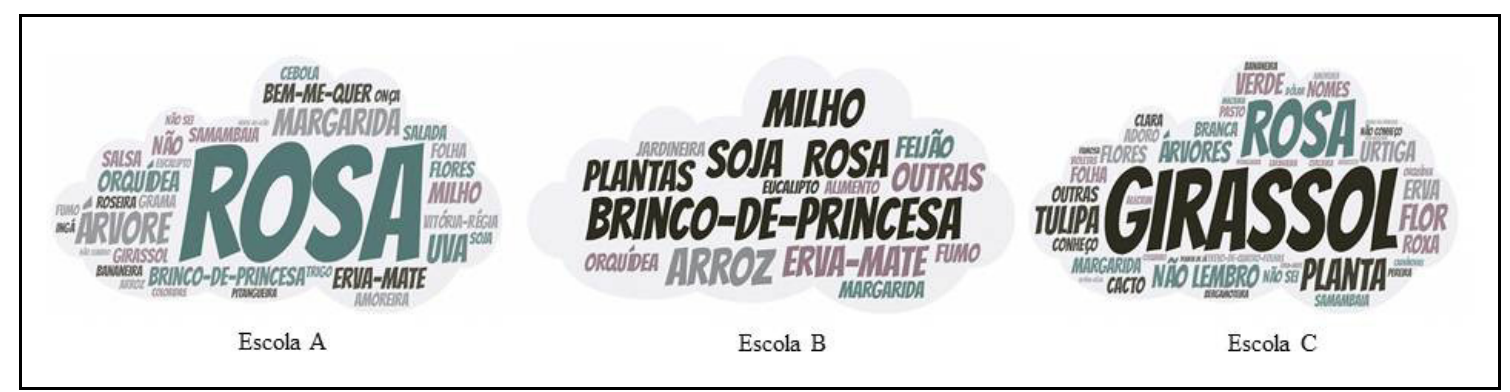

Figura 05 - Plantas da região citadas

Fonte: Dados da pesquisa

De acordo com a questão, as plantas mais citadas pelos estudantes foram: "brinco-deprincesa", "bem-me-quer", "erva-mate", "girassol", "rosa", entre outras. Os estudantes das escolas A e B citaram várias monoculturas, como, arroz, soja, milho e fumo, acredita-se que tais respostas estão associadas ao fato das escolas se localizarem no interior do Estado do RS, possibilitando um maior contato dos estudantes com a produção agrícola. Na escola $\mathrm{B}$, que está inserida na área rural, foi a que mais citou as monoculturas como plantas da região. 
Ensino, Saúde e Ambiente - V13 (1), pp. 31-56, Abr. 2020

As transformações da vegetação nativa do Pampa para a produção agrícola e plantações de espécies, está se tornando muito comum, e assim percebido como algo natural pelas crianças. A pesquisa de Castro (2018) com estudantes do ensino fundamental anos finais e ensino médio, demostrou que eles apresentam uma compreensão reduzida sobre monoculturas e espécies exóticas. Desse modo, acredita-se que esta confusão ocasionada, se dê pelo fato dos estudantes além de não conhecerem plantas características do Pampa, podem acreditar que as monoculturas fazem parte deste bioma.

Conforme Ziller (2016) a degradação ambiental causada pelo manejo de plantas exóticas é imensurável, pois estas apresentam uma grande adaptação aos "novos" locais. Assim, defende-se a importância de abordar tais questões em sala de aula.

$\mathrm{Na}$ questão 08 do Bloco 03, foi solicitado que aos estudantes que fizessem uma representação gráfica (desenho) sobre o que eles entendiam por bioma Pampa. Cabe ressaltar, que os desenhos da escola C tiveram influência do termo "Pampa Gaúcho", o qual foi utilizado na formulação da pergunta, e que posteriormente foi retirado para a aplicação nas outras escolas.

De acordo com Riva et al. (2010) as representação gráficas, os desenhos, proporcionam uma indicação sobre o desenvolvimento da criança, refletindo cada etapa. Assim, a expressão da criança pela arte reúne diversos elementos de sua experiência, ou seja, através desse tipo de representação a criança exprime a sua forma de ver o ambiente.

$\mathrm{Na}$ análise das representações gráficas, pode-se observar que apenas quatro estudantes não quiseram expressar sua percepção sobre o bioma Pampa, sendo que na escola $\mathrm{A}(\mathrm{n}=3)$ não quiseram responder e escola $\mathrm{C}(\mathrm{n}=1)$ também não.

Conforme mencionado anteriormente, foram criadas duas categorias para agrupar as representações gráficas, sendo que na categoria "Paisagens Urbanizadas" agruparam-se os desenhos que apresentavam em sua estrutura elementos prediais, de vias urbanas, de poluição e de influência humana na transformação da paisagem, conforme mostra a figura (06) abaixo. 
Ensino, Saúde e Ambiente - V13 (1), pp. 31-56, Abr. 2020

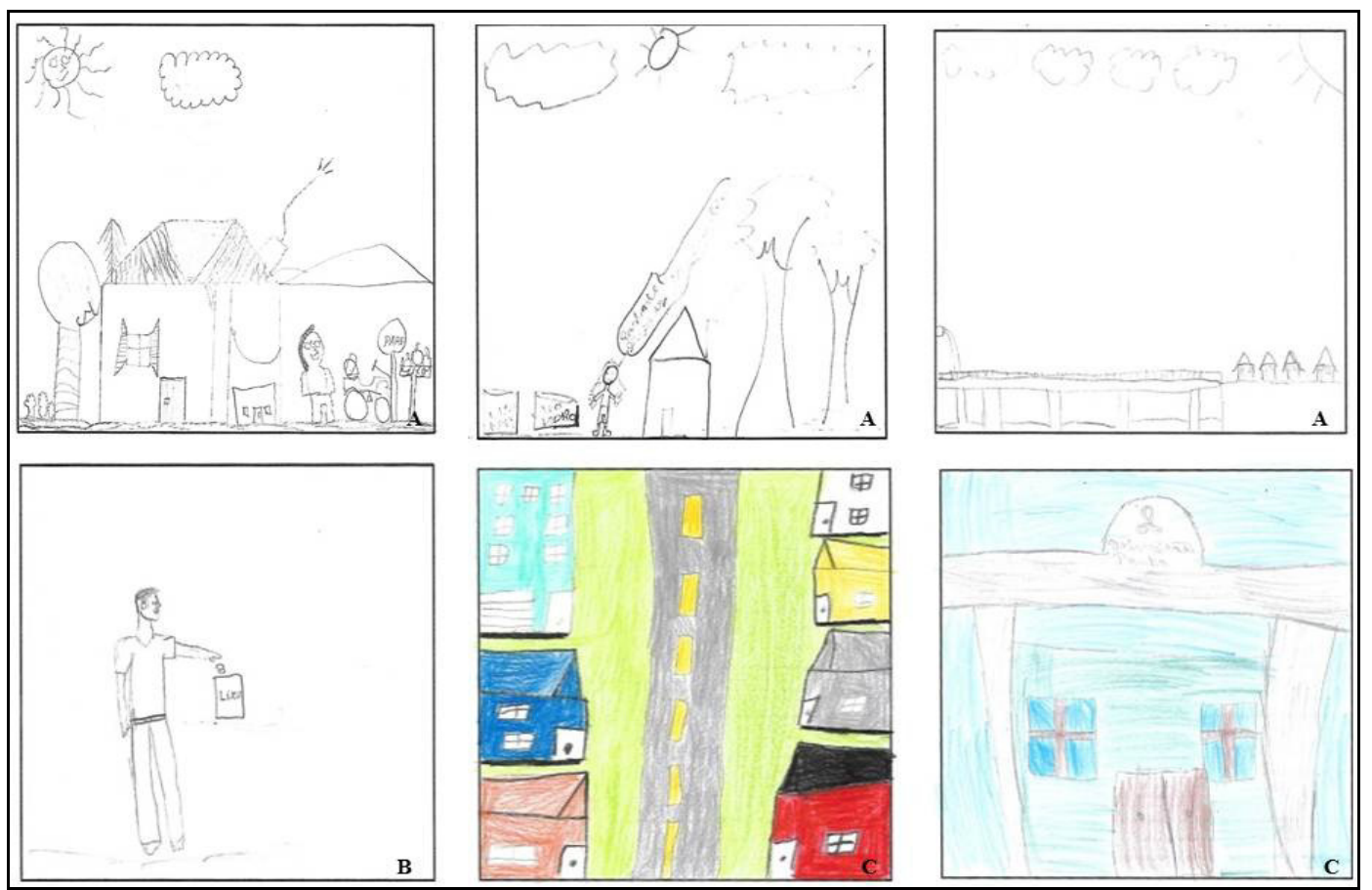

Figura 06 - Representações artísticas da categoria Paisagem Urbanas

Fonte: Dados da pesquisa

As representações gráficas da categoria "Paisagens urbanizadas" apresentaram elementos como casas, carros, praças, lixeiras, lixo, esgoto, ruas, representada por todas as escolas A $(n=8), B(n=3)$ e C $(n=3)$.

Na categoria, "Paisagens Rurais" foram agrupadas representações gráficas que apresentaram em sua estrutura elementos voltados ao campo, onde o destaque é o relevo, a vegetação e os animais, sem construções prediais aglomeradas, como pode ser observado na figura (07) abaixo.

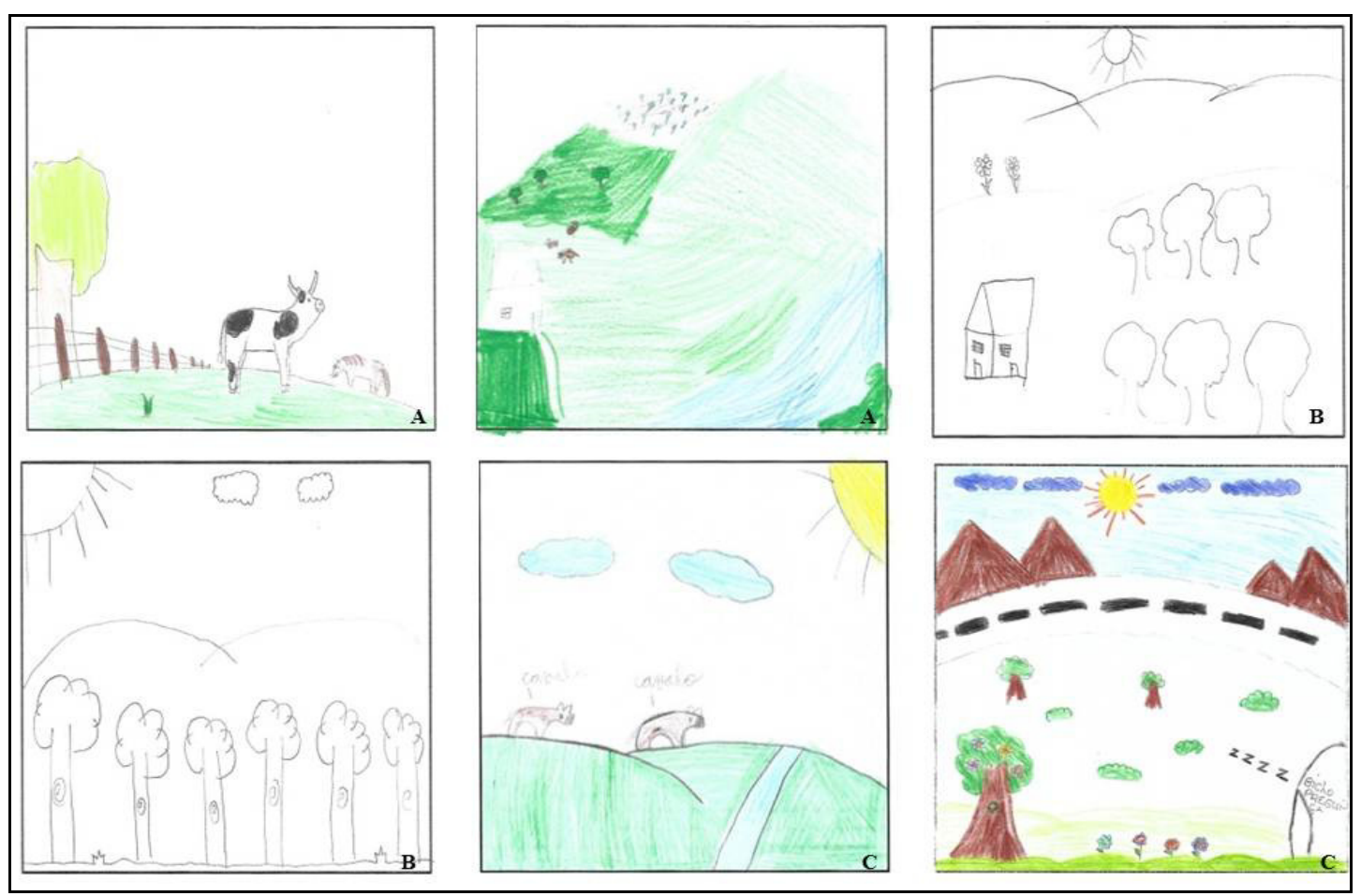


Ensino, Saúde e Ambiente - V13 (1), pp. 31-56, Abr. 2020

Figura 07 - Representações artísticas da categoria Paisagem Rurais Fonte: Dados da pesquisa

As representações apresentaram o ambiente do campo, os animais presentes nesses ambientes, mas também fatores antrópicos como casas, estradas, cercas, garrafa térmica, a paisagem do seu ambiente, a paisagem rural foi a mais representativa entre os desenhos, de acordo com as representações gráficas obteve-se um total de 65 desenhos, onde na escola A $(n=13)$, na escola $B(n=13)$ e na $C(n=39)$.

De acordo com Santos e Sartorello (2019, p. 914) “a separação entre paisagem natural e cultural reafirma o papel do homem como agente transformador da natureza e torna possível compreender a organização do espaço e dos problemas ambientais.”.

Assim, a partir da análise das representações gráficas, destacam-se os desenhos da escola C dentro da categoria "Paisagens Rurais", pois 17 desenhos tiveram a presença de elementos relacionados às vestimentas típicas da RS, seus costumes como o chimarrão, a prenda, o peão e o cavalo, como pode ser observado na figura (08) abaixo.

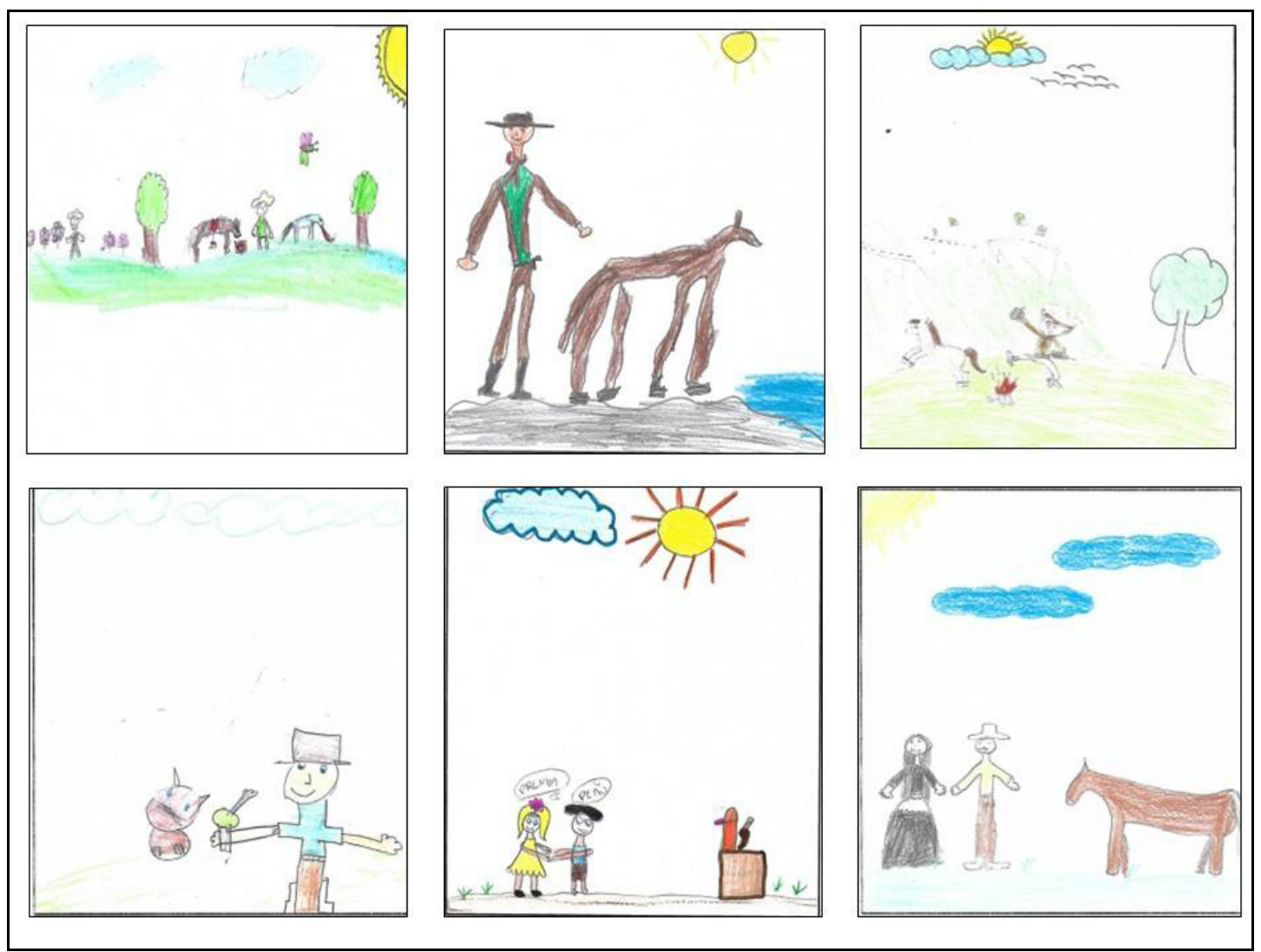

Figura 08 - Representações artísticas da categoria Paisagem Rurais com elementos Culturais Associados, na escola C.

Fonte: Dados da pesquisa

A paisagem representada assemelhou-se ao campo, sem a presença de muitas árvores na paisagem natural, por isso acredita-se que a presença do termo "Pampa Gaúcho" influenciou na representação do ambiente natural da região, ou seja, ao bioma Pampa. 
A partir das representações gráficas, é possível inferir que os estudantes que participaram da pesquisa demonstraram conhecimentos ingênuos sobre a paisagem natural do Pampa, através de elementos naturais, como o sol, as nuvens, as árvores, as flores, os frutos, a grama e os rios, contudo, de forma não caracterizada de acordo com o esperado para a paisagem do bioma Pampa. Esses dados se assemelham com os encontrados em outras pesquisas realizadas por Martinho e Talamoni (2007), Aires e Bastos (2011), Garrido e Meirelles (2014) os quais estudaram esse fenômeno para outros ecossistemas.

Paris et al. (2016, p. 118) explica que o desconhecimento sobre o bioma em foco, ocorre porque "Provavelmente, nas escolas da região, não acontece o estudo sobre as espécies vegetais e animais do bioma Pampa”, o que pode ser justificado pelo fato de que estes conteúdos não estejam contemplados nos livros didáticos utilizados durante as aulas. Assim, desconsidera-se a aprendizagem possibilitada a partir da CTSA que permita aos estudantes uma educação em Ciências mais contextualizada, tornando-os capazes de interagir com o meio que os rodeia, bem como para tomarem decisões conscientes e necessárias à resolução de problemas do cotidiano (FERNANDES, PIRES, DELGADO-IGLESIAS, 2018).

Outra análise possível é acerca da preocupação com o meio ambiente, a qual foi bastante descrita através do aparecimento de elementos como a poluição, o desmatamento, o reflorestamento e o lixo, tanto nos desenhos, como nas respostas das questões.

Ainda, em relação aos dados coletados, foi possível perceber que a escrita dos estudantes apresentou-se de forma diferente à esperada, com inadequações da língua portuguesa e algumas palavras não foram transcritas, devido à falta de compreensão pelos pesquisadores. Esse fator remete mais uma vez, a um possível ensino fragmentado e descontextualizado (PESSANO et al., 2013), podendo estar também relacionado a dificuldade de aprendizagem destes estudantes.

Desse modo, as imagens, valores e percepções que os estudantes têm de sua realidade podem fornecer ao professor subsídios para compreender as relações estabelecidas cotidianamente no plano individual e coletivo destes com o meio em que vivem. Assim, conforme Ribeiro e Silva (2012) a investigação das concepções ambientais dos alunos se torna um meio para a obtenção de informações relevantes para a elaboração de atividades e projetos de educação ambiental nas escolas.

\section{CONSIDERAÇÕES FINAIS}

De acordo com o objetivo proposto nesta pesquisa de investigar a percepção dos estudantes de três escolas estaduais do $5^{\mathrm{a}}$ ano do Ensino Fundamental sobre o bioma Pampa, e a partir da análise dos dados encontrados, foi possível fazer alguns apontamentos. 
Inicialmente, infere-se que os estudantes apresentaram percepções fragmentadas e distorcidas sobre o ambiente natural, o bioma Pampa. Visto que, tiveram dificuldades em associar o tema bioma Pampa com o ambiente em que vivem, não reconhecendo-o, embora o estudo desta temática esteja previsto nos documentos oficiais para esta etapa escolar.

Identificou-se também, que os elementos citados pelos estudantes em suas respostas foram generalistas e poucas apresentavam características relacionadas ao Pampa.

Observou-se que somente os estudantes da escola C conseguiram caracterizar o bioma Pampa nos desenhos, o que acredita-se que esteja relacionado a utilização do termo "Pampa Gaúcho" na elaboração da questão. Os desenhos apresentaram o campo, com poucas árvores, o chimarrão e a cultura do Gaúcho, no entanto, após a percepção desta possível influência do termo, ele foi retirado do enunciado da questão para posterior aplicação nas demais escolas participantes da pesquisa. Desse modo, verificou-se que nas outras escolas pesquisadas, após a retirada do termo, esta referência ao gaúcho não apareceu.

Destaca-se também, o desconhecimento do conteúdo, quando os estudantes em suas respostas citam o cultivo de monoculturas e de espécies exóticas como plantas e animais da região do Pampa, demonstrando assim, à falta de compreensão na definição e exemplificação dos termos, bem como, a naturalização da conversão dos campos nativos para a agricultura.

Os resultados encontrados nesta pesquisa podem estar relacionados a inúmeros fatores, entre os quais podemos apontar uma possível dificuldade dos professores em abordar os conteúdos do ensino de Ciências nos anos iniciais, devido a sua formação inicial. Desse modo, difundem um ensino de Ciências descontextualizado das questões CTSA, ocasionando o desconhecimento da importância dos ecossistemas locais para a manutenção da biodiversidade.

Nesse sentido, aponta-se para a necessidade da realização de processos de formação junto aos professores, para que venham a contribuir nesse sentido, possibilitando um ensino de Ciências mais contextualizado e dinâmico.

Portanto, momentos como esse, apresentados neste trabalho, torna possível compreender as diferentes percepções sobre o meio ambiente, contribuindo para que as pessoas reflitam sobre suas ações, possibilitando assim, a preservação e conservação do meio ambiente. Dessa forma, sugere-se que o levantamento das percepções sobre o ambiente em que as pessoas vivem, seja uma etapa anterior a qualquer projeto que envolva a relação entre homem e ambiente, pois somente a partir disso é que podem se desenvolver ações eficazes no sentido de contribuir para a obtenção de consciência ambiental.

Por fim, cabe mencionar que este trabalho não teve o objetivo de apontar que escolas, ou quais professores foram responsáveis pelos resultados insatisfatórios dos 
Ensino, Saúde e Ambiente - V13 (1), pp. 31-56, Abr. 2020

estudantes, mas efetuar um diagnóstico sobre a percepção do bioma Pampa pelos estudantes, tendo em vista a sua importância nos processos ambientais, econômicos e sociais.

\section{AGRADECIMENTO}

CNPq e CAPES pelo auxílio financeiro.

\section{REFERÊNCIAS}

AIRES, B. F. da C.; BASTOS, R. P. Representações sobre meio ambiente de alunos da educação básica de Palmas (TO). Ciência \& Educação, v. 17, n. 2, p. 353-364, 2011.

ALMEIDA, A.; VASCONCELOS, C.; TORRES, J. Perceções do bem-estar animal em crianças do $1^{\circ}$ ciclo. Investigações em Ensino de Ciências, v.18, n.1, p. 161-176, 2013.

AULER, D.; DELIZOICOV, D. Alfabetização científico-tecnológica para quê? Ensaio: pesquisa em educação em ciências, v. 3, n. 1, p. 105-115, 2001.

BARDIN, L. Análise de Conteúdo. São Paulo: ed. 70, 2011.

BATISTA, M. C.; FUSINATO, P. A.; RAMOS, F. P. Contribuições de uma oficina de astronomia para a formação inicial de professores dos anos iniciais. Ensino, Saúde e Ambiente, v.10, n.2, p. 107-128, 2017.

BENCKE, G.A.; CHOMENKO, L.; SANTANA, D, M. O que é o Pampa? In: CHOMENKO, L., BENCKE, G.A. (orgs.). Nosso Pampa Desconhecido. 1 ed. Porto Alegre: Fundação Zoobotânica do Rio Grande do Sul, 2016.

BIZZO, N. Ciências: fácil ou difícil? 1. ed. São Paulo: Biruta, 2009.

BOLDRINI, I. I. et al. Bioma Pampa: diversidade florística e fisionômica. Porto Alegre: Editora Pallotti, 2010.

BRASIL. Parâmetros Curriculares Nacionais: Introdução aos parâmetros curriculares nacionais. Secretaria de Educação Fundamental. Brasília: MEC/SEF, 1997.

BRASIL. Ensino fundamental de nove anos: passo a passo do processo de implantação. Ministério da Educação. Secretaria de Educação Básica, 2009.

BRASIL. Monitoramento do Desmatamento nos Biomas Brasileiros por Satélite. Ministério do Meio Ambiente. 1. ed. Brasília, DF, p. 29, 2011. Disponível em: https://www.mma.gov.br/projeto-de-monitoramento-do-desmatamento-nos-biomasbrasileiros-por-sat\%C3\%A9lite-pmdbbs. Acesso em: 07 maio 2019.

BRASIL. Base Nacional Comum Curricular - Versão final. Ministério da Educação, MEC. 2018.

BRONDANI, C. J.; HENZEL, M. E. Análise sobre a conscientização ambiental em escolas da rede municipal de ensino. REVBEA, v.5, n. 1, p. 37- 44, 2010.

CARVALHO, A. M. P. Introduzindo os alunos no universo das ciências. In: WERTHEIN, J.; CUNHA, C. da (Orgs.). Educação Científica e Desenvolvimento: O que pensam os cientistas?. 2 ed. Brasília: UNESCO/ Instituto Sangari, 2009. 
CASTRO, L.R.B. O bioma Pampa como temática de investigação no ensino básico no município de Uruguaiana-RS. 2018. 180p. Dissertação (Mestrado Educação em Ciências: Química da Vida e Saúde) - Universidade Federal de Santa Maria, Santa Maria, RS, 2018.

CRUZ, R. C.; GUADAGNIN, D. L. Uma pequena história ambiental do Pampa: proposta de uma abordagem baseada na relação entre perturbação e mudança. In: COSTA, B.P. da, QUOOS, J.H., DICKEL, M.E.G. (orgs). A sustentabilidade da Região da Campanha-RS: Práticas e teorias a respeito das relações entre ambiente, sociedade, cultura e políticas públicas. Santa Maria: UFSM, p.155-179, 2010.

FERNANDES, I. M. B.; PIRES, D. M.; DELGADO-IGLESIAS, J. Perspetiva Ciência, Tecnologia, Sociedade, Ambiente (CTSA) nos manuais escolares portugueses de Ciências Naturais do $6^{\circ}$ ano de escolaridade. Ciência \& Educação, Bauru, v. 24, n. 4, p. 875-890, 2018 .

FRACALANZA, H.; AMARAL, I. A.; GOUVEIA, M. S. F. O ensino de ciências no primeiro grau. São Paulo: Atual, 1986.

GARRIDO, L.S; MEIRELLES, R.M.S. Percepção sobre meio ambiente por alunos das séries iniciais do Ensino Fundamental: considerações à luz de Marx e de Paulo Freire. Ciência \& Educação, v. 20, n.3, p. 671-685, 2014.

GIL, D.; VILCHES, A. Contribución de la ciencia a la cultura ciudadana. Cultura y Educación, Barcelona, v. 16, n. 3, p. 259-272, 2004.

HEYWOOD, V. H. Global biodiversity assessment. Cambridge: Cambridge University Press, 1995.

IBAMA. Portaria nº 93/1998. Alterações Importação e Exportação de Fauna Silvestre Nativa ou Exótica; Lista de Fauna Doméstica para fins de Operacionalização do Ibama.

KELLERT, S. R. Values and perceptions of invertebrates. Conservation Biology, v.7, n. 4, p. 845-855, 1993. Disponível em: https://doi.org/10.1046/j.1523-1739.1993.740845.x. Acesso em: 28 jul. 2018.

KRASILCHIK, M. Reformas e realidade: o caso do ensino das ciências. São Paulo em Perspectiva, v. 14, n. 1, p. 85-93, 2000.

MARTINHO, L. R.; TALAMONI, J. L. B. Representações sobre meio ambiente de alunos da quarta série do ensino fundamental. Ciência \& Educação, v. 13, n. 1, p. 1-13, 2007.

MINAYO, M. C. de S. Pesquisa Social. Teoria, método e criatividade. 18 ed. Petrópolis: Vozes, 2001.

OVERBECK, G. E. et al. Os Campos Sulinos: um bioma negligenciado. In: PILLAR, V.P. et al. (Eds.). Campos Sulinos - conservação e uso sustentável da biodiversidade. 1 ed. Brasília: MMA, 2009.

PARIS, A. M. V. et al. O que os jovens gaúchos que residem na Mata Atlântica pensam sobre o Pampa?. Perspectiva. v. 40, n. 152, p. 111-123, 2016.

PAZ, A. L. G.; ROMANOWSKI, H. P.; MORAIS, A. B. B. Borboletas frugívoras do centro oeste do Rio Grande do Sul, Brasil (Lepidoptera: Nymphalidae). SHILAP revista de Lepidopterología, vol. 42, n. 167, p. 409-422, 2014. 
PESSANO, E. F. C. et al. Percepções socioambientais de estudantes concluintes do ensino fundamental sobre o rio Uruguai. Ciências \& ideias, v.4, n.2, p. 61-8, 2013.

PÉREZ, L. F. M.; CARVALHO, W. L. P. de. Contribuições e dificuldades da abordagem de questões sociocientíficas na prática de professores de ciências. Educação e Pesquisa, São Paulo, v. 38, n. 03, p. 727-741, 2012.

PRAIS, J. L. de S.; ROSA, V. F. da. Nuvem de palavras e mapa conceitual: estratégias e recursos tecnológicos na prática pedagógica. Nuances: estudos sobre Educação, v. 28, n. 1, p. 201-219, 2017.

PROFICE, C. et al. Janelas para a percepção infantil de ambientes naturais. Psicologia em Estudo, Maringá, v. 18, n. 3, p. 529-539, 2013.

RIBEIRO, L.L.; SILVA, J.B da. Uma concepção sobre educação ambiental e meio ambiente com alunos de 8 e 9 anos: primeiras impressões e considerações acerca dos saberes ambientais na escola estadual anexa a SUPAM. OBSERVATORIUM: Revista Eletrônica de Geografia, v.4, n.12, p. 128-143, dez. 2012.

RIO GRANDE DO SUL. Referencial Curricular Gaúcho: Ciências da Natureza. Secretaria de Estado da Educação, Departamento Pedagógico. v.1. Porto Alegre. 2018. Disponível em: http://portal.educacao.rs.gov.br/Portals/1/Files/1530.pdf. Acesso em: 28 junho de 2019.

RIVA, P. B. da et al. Representações ambientais de alunos da $1^{\text {a }}$ série do ensino médio em uma escola estadual do município de Porto Rico - PR. In: II Simpósio Nacional de Ensino de Ciência e Tecnologia, outubro de 2010, ISSN: 2178-6135. Artigo número: 202.

Disponível em: http://www.sinect.com.br/anais2010/artigos/EC/202.pdf. Acesso em: 29 junho de 2019.

ROCKSTRÖM, J., et al. A safe operating space for humanity. Nature, v. 461 p. 472-475, 2009. Disponível em: https://www.nature.com/articles/461472a. Acesso em 29 junho de 2019.

RODRIGUES, L. L.; FARRAPEIRA, C. M. R. Percepção e educação ambiental sobre o ecossistema manguezal incrementa as disciplinas de ciências e biologia em escola pública do Recife-PE. Investigações em Ensino de Ciências, v. 13, n.1, p. 79-93, 2008.

SANTOS, W. A. dos; SARTORELLO, R. Percepção e paisagem no cotidiano de escolas inseridas em paisagens rurais e urbanas. Ciência \& Educação, v. 25, n. 4, p. 911-926, 2019.

SASSERON, L.H. Alfabetização científica, ensino por investigação e argumentação: relações entre ciências da natureza e escola. Revista Ensaio, v. 17, n. spe, p. 49-67, 2015.

SCHWARZ, M. L. et al. 'Chuva, como te queremos!': representações sociais da água através dos desenhos de crianças pertencentes a uma região rural semiárida do México. Ciência \& Educação, v. 22, n.3, p. 651-669, 2016.

SNADDON, J. L et al. Children's Perceptions of Rainforest Biodiversity: Which Animals Have the Lion's Share of Environmental Awareness?. PLOS ONE, v.3, n.7, 2008.

SNADDON, J. L; TURNER, E. C. A child's eye view of the insect world: perceptions of insect diversity. Environmental Conservation, v. 34, p. 33-35, 2007. 
SOARES, A. C.; MAUER, M. B.; KORTMANN, G. L. Ensino de ciências nos anos iniciais do ensino fundamental: possibilidades e desafios em Canoas-RS. Revista Educação, Ciência e Cultura, v. 18, n. 1, p. 49-61, 2013.

SOUSA, G. L. de et al. A Importância da educação ambiental na escola nas séries iniciais. Revista Faculdade Montes Belos, v. 4, n. 1, 2011.

SUERTEGARAY, D. M. A.; SILVA, L. A. P. Tchê Pampa: histórias da natureza gaúcha. In: PILLAR, V. P. et al. (Eds.). Campos Sulinos - conservação e uso sustentável da biodiversidade. 1 ed. Brasília: MMA, 2009.

TUAN, Y. F. Espaço e lugar: a perspectiva da experiência. São Paulo: DIFEL, 1983.

UNESCO. Ensino de Ciências: o futuro em risco. 2005. Disponível em: https://unesdoc.unesco.org/ark:/48223/pf0000139948. Acesso em: 17 abr. 2019.

VERRASTRO, L.; BORGES-MARTINS, M. C. Biodiversidade de Répteis. In: PILLAR, V.P; LANGE, O. (Eds.). Os Campos do Sul. Porto Alegre: UFRGS, 2015.

VIECHENESKI, J. P.; CARLETTO, M. R. Ensino de Ciências e Alfabetização Científica nos anos iniciais do Ensino Fundamental: um olhar sobre as escolas públicas de Carambeí. In: VIII Encontro Nacional de Pesquisa em Educação em Ciências - ENPEC, Anais, 2011. Disponível em: http://www.nutes.ufrj.br/abrapec/viiienpec/resumos/R0741-1.pdf. Acesso em: 18 abr. 2019.

VIECHENESKI, J. P.; LORENZETTI, L.; CARLETTO, M. R. Desafios e práticas para o ensino de ciências e alfabetização científica nos anos iniciais do ensino fundamental. Atos de Pesquisa em Educação, v. 7, n. 3, p. 853-876, 2012.

WAGLER, R.;WAGLER, A. Arthropods: Attitude and incorporation in preservice elementary teachers. International Journal of Environmental \& Science Education, v. 6, n. 3, p. 229250, 2011. Disponível em:

https://www.researchgate.net/publication/265194176_Arthropods_Attitude_and_incorporatio n_in_preservice_elementary_teachers. Acesso em: 28 jul. 2019.

WEILBACHER, M. The renaissance of the naturalist. The Journal of Environmental Education, v. 25, n. 1, p. 4-7, 1993. Disponível em: https://www.tandfonline.com/doi/abs/10.1080/00958964.1993.9941937. Acesso em: 28 jul. 2019.

WORTMANN, M.L.C.; RIPOLL, D.; POSSAMAI, L. Educação ambiental corporativa para crianças: analisando a animação Peixonauta do Discovery Kids. Perspectiva, v. 30, n. 2, p. 371-394, 2012.

ZILLER, S. Estratégias e políticas públicas para o controle das espécies exótica invasoras. Publicações do Projeto RS Biodiversidade. Secretaria do Ambiente e Desenvolvimento Sustentável, Instituto Hórus. 1. ed, Porto Alegre, 2016. 


\section{SOBRE OS AUTORES}

\section{AUTOR 1.}

Graduada em Licenciatura em Ciências Biológicas (IFFar - SVS). Mestre em Educação em Ciências: Química da Vida e Saúde pela Universidade Federal de Santa Maria. Doutoranda do PPG Educação em Ciências, área ensino, pela Universidade Federal do Pampa. Nesse trabalho realizou a coleta e análise dos dados e redação do texto.

\section{AUTOR 2.}

Graduada em Licenciatura em Ciências Biológicas (IFFar - SVS). Mestre em Educação em Ciências: Química da Vida e Saúde pela Universidade Federal de Santa Maria. Doutoranda do PPG Educação em Ciências, área ensino, pela Universidade Federal de Santa Maria. Nesse trabalho auxiliou na redação do texto e interpretação dos dados.

\section{AUTOR 3.}

Graduado em Ciências Biológicas (PUCRS). Especializado em Licenciamento Ambiental (FGF). Mestre em Educação em Ciências Química da Vida e Saúde pela Universidade Federal de Santa Maria. Doutorando do PPG Educação em Ciências, área ensino, pela Universidade Federal do Pampa. Nesse trabalho realizou a coleta e análise dos dados e redação do texto

\section{AUTOR 4.}

Graduado em Ciências Biológicas (PUCRS), Especialista em Educação Ambiental (FACISA). Mestre e Doutor em Educação em Ciências (UFSM). Atualmente é Professor Universidade Federal do Pampa e Professor Permanente do PPG em Educação em Ciências, Química da Vida e Saúde (UNIPAMPA). Auxiliou no planejamento das atividades, orientou quanto ao embasamento teórico, análise dos dados e discussão dos resultados. 